\title{
Objects and the Representation of War in Military Museums
}

James Scott*

\begin{abstract}
This paper reflects upon the ability of a military museum to create diverse representations of war, through the use and interpretation of its objects. In this type of museum, war can be presented as being both a positive or negative phenomenon. For many people, a visit to a military history museum is the one of the main ways that a person will learn about war, aside from its portrayal in education, the media or in film and television. These museums have great influence in representing war. This is particularly true in Northern Ireland where representations of conflict have the potential to widen the gap between communities in an already divided society.

How objects affect the creation of representations of war can depend on which types of object are displayed, in what context they are displayed, their physical condition and also the way in which the objects are connected with people or individuals (Saunders, 2004; Dudley 2010). This paper examines three approaches to displaying objects in the regimental museums of Northern Ireland. These have been termed the celebratory approach, the sanitized approach and the realistic approach.
\end{abstract}

Key words: Difficult histories, exhibition, material culture, displaying violence

\section{Introduction}

This paper reflects upon the ability of a military museum to create diverse representations of war through the use and interpretation of objects. In this type of museum, war can be presented as being a positive and/or negative phenomenon, something that can evoke feelings of pride, guilt or even revulsion. Also discussed here is how the different methods of displaying the objects affect the visitor and determine their impressions of war. This can be in terms of what they come to believe war is like as an experience, but also their attitudes and opinions towards violent conflict more generally.

Traditionally, the visitor base of regimental museums has been serving or veteran soldiers, but increasingly, they are becoming an attraction for ordinary people, school groups and tourists. For many people, a visit to a military history museum is one of the main ways that they will learn about war, aside from its portrayal in education, the media or in film and television. The influence that military museums have in promoting a particular representation of war, is considerable. This is particularly true in Northern Ireland, where representations of conflict have the potential to widen the gap between communities in an already divided society. Are these museums obligated to represent war in a way suited not only to the traditional purposes of the armed forces, but to those who have never experienced war? Richard Sandell (2003) discussed the social role of museums and their potential impact on society, particularly in displaying a plurality of viewpoints and representations for the benefit of everyone. This thinking is echoed in the Department of Culture and Learning (DCAL) Northern Ireland Museum Policy Document (2011):

Museums have an important role to play in society and are uniquely placed to deliver public benefits on a number of fronts. They are not for the few but for everyone and have 
local, national and international reach. Museums should be respected and reliable sources of information and through their collections and knowledge provide real connections to the past, engage with the present and open windows to the future.

If regimental museums wish to adhere to the same guidelines as other museums, surely they must communicate their history effectively for the benefit of those both inside and outside of the regimental milieu.

The research that this paper is based on was predominately carried out in the regimental museums of Northern Ireland: the Royal Irish Fusiliers Museum, Armagh; the Inniskillings Museum, Enniskillen; and the Royal Ulster Rifles Museum, Belfast. Here, creating a representation of war is arguably more contentious; with the regimental museums being seen by nationalist critics 'as a bastion of unionism' 1 and a 'cold place for Catholics'. Nevertheless, the fact the museums investigated were, for that reason, slightly atypical, did not, in the end, detract from the universal applicability of the findings. Other observations have been made based upon the author's experience working at the Royal Engineers Museum, Gillingham. Surveys, focus groups, interviews and gallery observation were used at the above museums to study the varying methods of displaying different types of military object and how this can create different representations of war.

It is certainly the case that objects have a promiscuity of meaning (Saunders, 2004) and interpretation of a particular object depends on existing knowledge and experience. Materiality and the physical appearance of an object also have an impact on the ways that they are perceived (Dudley, 2010). When objects are displayed in different ways they can communicate vastly different meanings and messages. This can be through textual interpretation, but also relates to how an object is juxtaposed with other objects, the condition of the object, its physical setting within its case and also the way in which an object is connected with people or individuals. When objects are viewed they trigger a particular set of perceptions and responses in the human subject depending on what meanings they were previously invested with, either by their previous owners, displayers or wider society (Dudley, 2010), and this is how objects can have agency or power over people.

Using objects appropriately in military museums can involve addressing several balances. Gieryn (1998) discussed how science museums find balance between presenting science in terms of accomplishment and the evil that it can produce. The same principle is applicable to regimental museums, as ultimately they must condemn war and yet practically all the achievements of the British Army are based upon it. The display of violence is another example of a balance; the desire to honestly and realistically depict war can interfere with a museum's narrative and potentially create a negative visiting experience. The three approaches discussed below reflect the overall balance that influence how war is represented. The 'Celebratory' approach creates a largely positive view of war by extolling the achievements of the military. The 'Sanitary' approach creates a more neutral display by placing objects in alternative contexts. In contrast, the 'Realistic' approach displays war in a 'warts and all' manner, in an overt attempt to remind visitors of the horrors of war. These names are by no means intended as being definitive; they have been used simply for the purpose of discussion and comparison.

\section{Celebratory Displays in Military Museums}

Some museum objects are presented and explained in terms of the triumphs and achievements that have resulted from war. This approach to displaying objects is very useful in achieving some of a military museum's functions, such as commemoration, fostering an esprit de corps, and encouraging recruitment. As Pearce explained, esprit de corps has historically been very important to the military; 'an essential ingredient in their fighting powers' (Pearce, 1999: 321). A significant part of a regimental museum's mandate in recounting history is that it is there to commemorate the fallen. Although commemoration itself cannot be described as celebratory, the respect and positive feelings people have towards the fallen can result in more positive or favourable interpretations of their history. It is easy to understand how the traditional purposes of these museums can cause them to foster a more celebratory approach. However, is the role of this type of museum evolving? As more regimental museums receive designation, are awarded more public funding and attract more schools and family groups, surely their output and the way they interpret conflict should also change and adapt? 


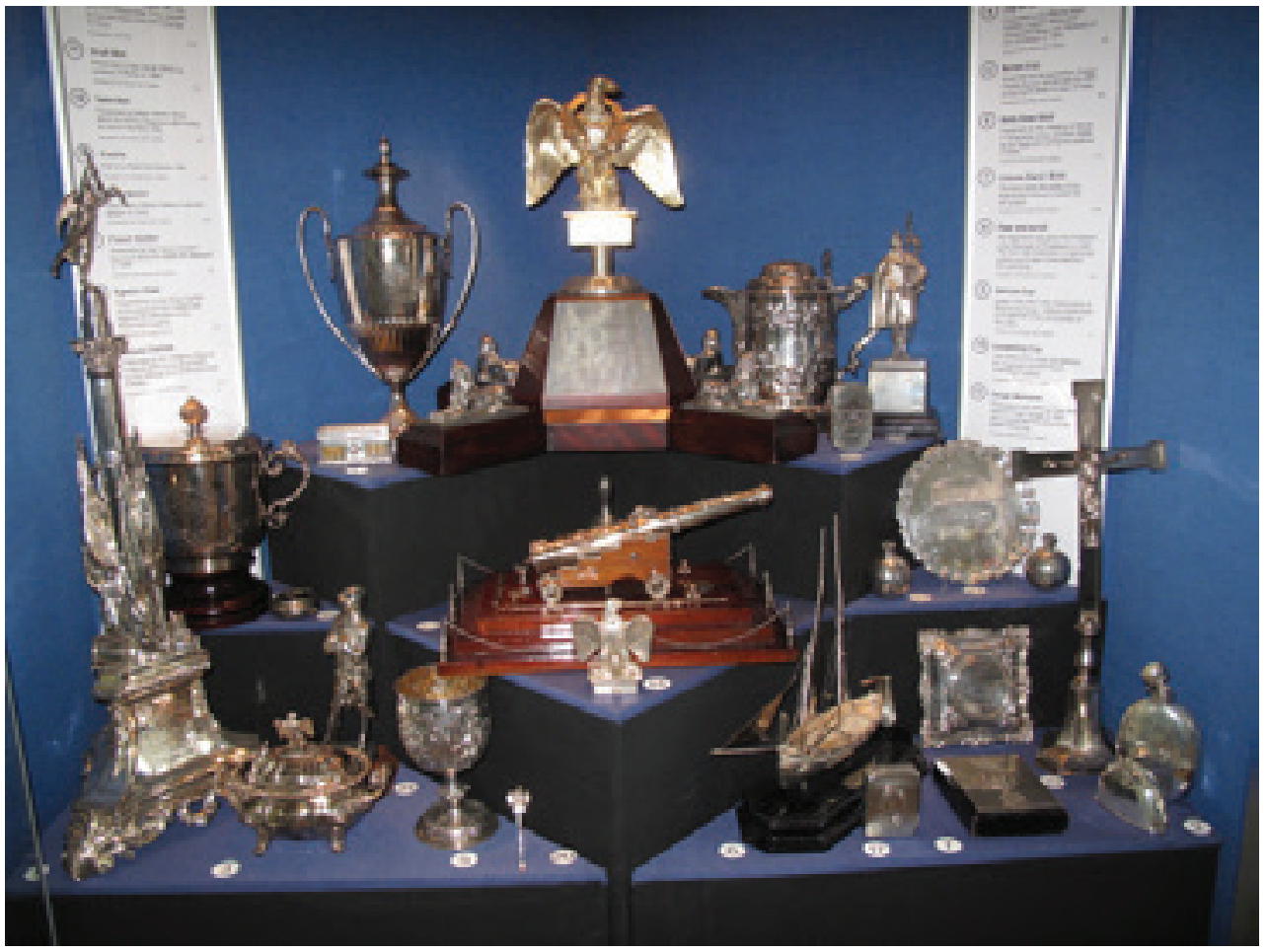

Fig 1. Silverware cabinet, courtesy of Royal Irish Fusiliers Museum

In the past, societies have represented war in very different ways. Most societies have at one point ennobled war and its soldiers to some degree. Nazi Germany would be an extreme example; 'National Socialism glorified war as the highest human experience' (O'Brian, 1997). Due to changes in warfare and within our society, representing war in an appropriate manner is a task fraught with problems. Celebratory displays can often incorporate elements of nationalistic narratives and are not immune to jingoism. The problem with this approach is that the visitor learns more about the positive side of armed conflict and this can create a distorted and one-sided representation of war.

One characteristic of this approach includes the use of objects brought back from conflicts, displayed in a way which emphasizes their status as a 'trophy' and which asserts the fact that that culture of origin has been dominated (Jones, 1996). The perceived value of these objects relate to the fact that they had been 'taken'. An example which demonstrates this occurred during the post-war years of the Imperial War Museum, as discussed by Cornish (2004). A set of German flags were purpose-bought and displayed within the museum for educational purposes. Veterans responded with outrage to the fact that they had not been taken from the enemy. From the veterans' point of view, the mandate in displaying such objects clearly came from the fact that they had been captured; it seemed absurd to them to display the iconography of the enemy in a purely educational sense.

Despite their potential to tell more of a balanced story about both sides of a conflict (as they often belonged to someone on the opposing side), these objects are often explained in terms of the achievements of the conquering force. The most prized example of a trophy object within the Royal Irish Fusiliers Museum is the French Eagle (Figure 1) captured at the Battle of Barossa. Such items are highly valued because of the glory and prestige that they add to the regiment. This is clear in the way that the Eagle is presented, housed in what resembles a trophy cabinet, posed amongst other pieces of silverware. Although a source of great pride for those associated with the regiment, there have been occasions where French 
tourists have complained about this display, suggesting that it creates friction and serves to reawaken old enmities with the French ${ }^{2}$. This 'trophy cabinet' effect serves to aestheticize the objects but in doing so inhibits thinking about what the object may have meant to its original owners in terms of cultural and personal value.

A further example can be found in the Royal Engineers Museum: a decorative piece of metalwork from the top of the tomb of the Sudanese leader, the Mahdi. This object features in a display relating to the campaign that followed General Charles Gordon's (RE) death at Khartoum (1885). The campaign was brutally successful and ended in the taking of the Mahdist capital of Omdurman and the destruction of the tomb. In its case there is little to explain this object's significance to those whom it originally belonged, to explain who the Mahdi was, or to question the right of the British soldiers to take it. It merely acts as a symbol that Gordon's death had been avenged (this is further eemphasized by the presence of a portrait of Gordon in the same case). In this way, objects like these can 'become a 'holy relic' about which there could be no critical discussion' (Dubin, 1999: 222). Are these types of museum 'temples' within which objects are worshipped, (Cameron 1971) or should they be more of a 'forum' within which there can be critical and democratic discussion concerning the objects? Today the taking of trophies on campaign is an offence taken seriously and it would be helpful to contextualise the object by commenting that it happened regularly in the past without punishment (sometimes it was even encouraged).

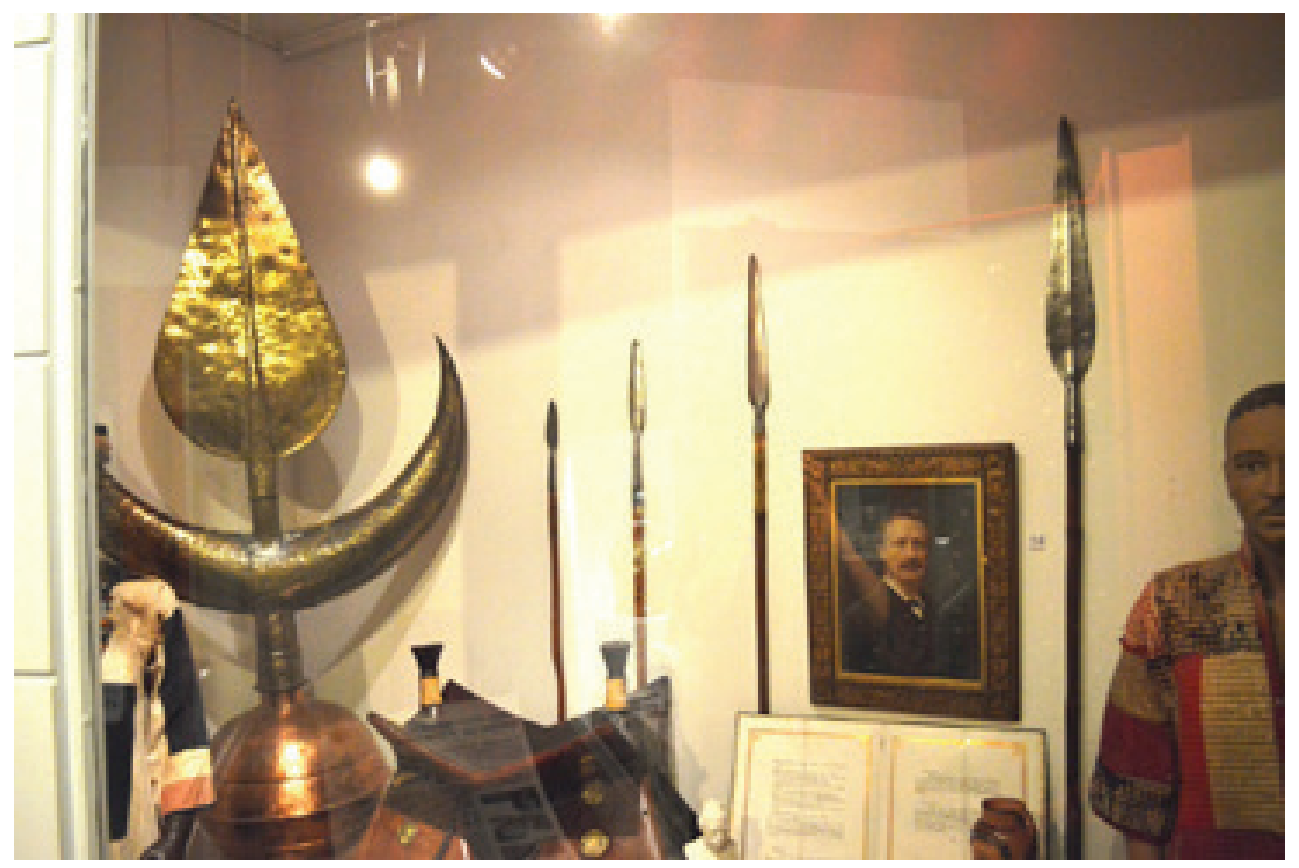

Fig 2. Decoration from the Mahdi's tomb (left), Royal Engineers Museum

Another characteristic of this approach is the use of objects that make the prestige of the regiment more visually accessible. In the regimental museums of Northern Ireland, there are far more examples of regimental silverware and adornments in the galleries than their English counterparts. This is because their regiments have been amalgamated and there are no longer as many messes to decorate. The museums contain large cabinets which house numerous silver pieces which have engraved upon them the sporting and military achievements of the regiment. This makes for a very celebratory display and this effect is furthered by the highly polished 


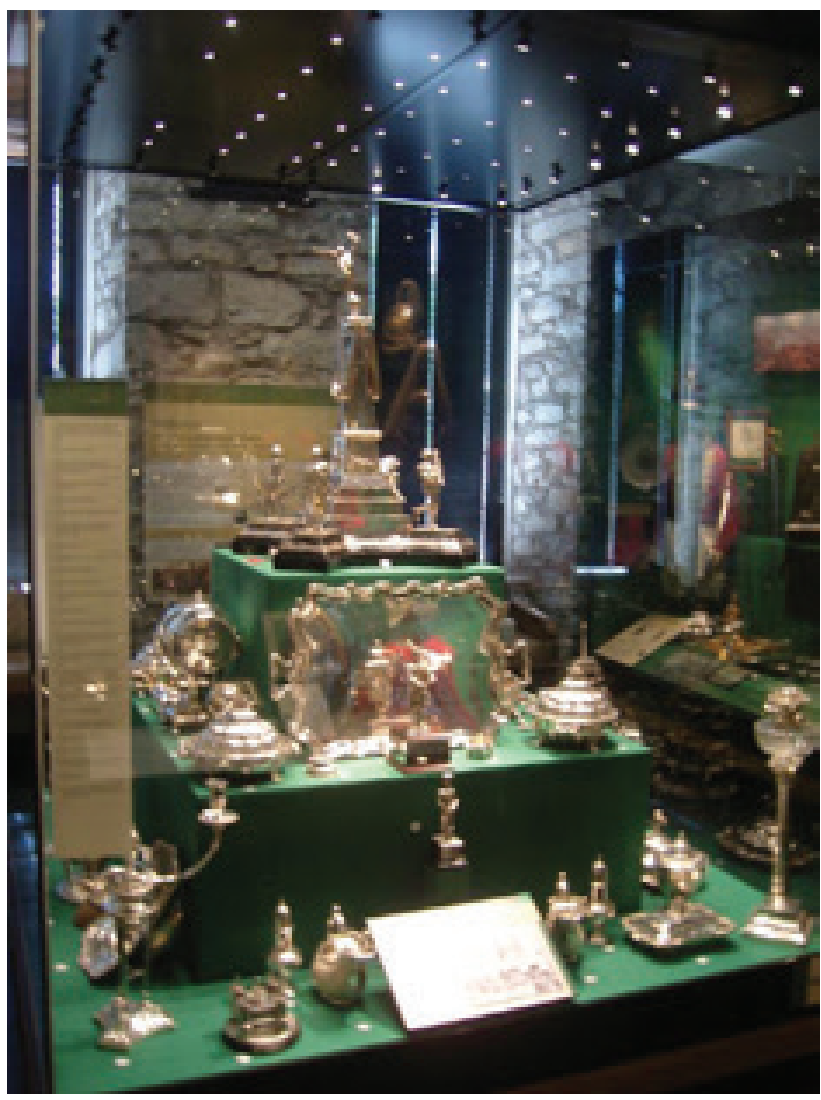

Figure 3. Silverware cabinet, courtesy of the Inniskillings Museum condition of these objects.

A similar effect can be achieved by the arrangement of large numbers of shiny medals, displayed en masse. It is arguable that medals have become what Walker (1997) termed 'objects of fascination'. Museum stores are full of remarkably similar medals which have been repetitively acquired in remarkably similar ways. Bound up in this is a desire to control and gain recognition (on behalf of the regiment) through the material world. The thinking behind this approach is that more is better. Although this creates an explicit visible representation of the regiment's prestige, it serves only to transform a medal from being a person's possession, the last physical embodiment of their service, into an ornament and a symbol of a regiment's pride. All of the examples mentioned above are aesthetically pleasing objects. Within military museums, the colourful scarlet uniforms, the polished, ornate sword blades and the exotic charm of the 'foreign' objects contribute to create a visually impressive display. Although this is often necessary to pull in visitors who know little about military objects ${ }^{3}$, criticism has been levelled at museums for overly aestheticizing war. Appadurai (1986) noted that in particular ethnographic objects can be exploited in this way. By placing the plunders of war in unlikely contexts, the appeal of these objects is accelerated or enhanced, due to the 'aesthetics of decontextualisation'.

A further feature of this approach is the use of nostalgic objects. Sporting objects, trench art and keepsakes all have their place in these museums. They are an important part of life for a soldier and can be used to show war in terms of morale and how soldiers have attempted to cope with war. However, their display does have the potential to trivialize conflict when combined with overly simplistic interpretations.

\section{The Sanitisation of Museum Objects}

This approach involves displaying military objects with potentially controversial meanings in a way which is more neutral. This is what Whitmarsh (2001) referred to as being a 'sanitized' approach. This is particularly the case with objects relating to the more violent side of war, such as firearms and bladed weapons. The balance here is between achieving a realistic view of war as being a violent thing, and not causing offence by being too realistic or by highlighting the violent activities carried out by the military. Veterans who have seen war do not want to re-experience past horrors and the museum-going public do not want to be offended. Unlike the previously discussed approach, it is not an overt attempt to create a positive view of war; 
it is merely a way of displaying the negative side in a 'safe' manner (Lubar, 1997) without spoiling the overall message that the museum wishes to put across.

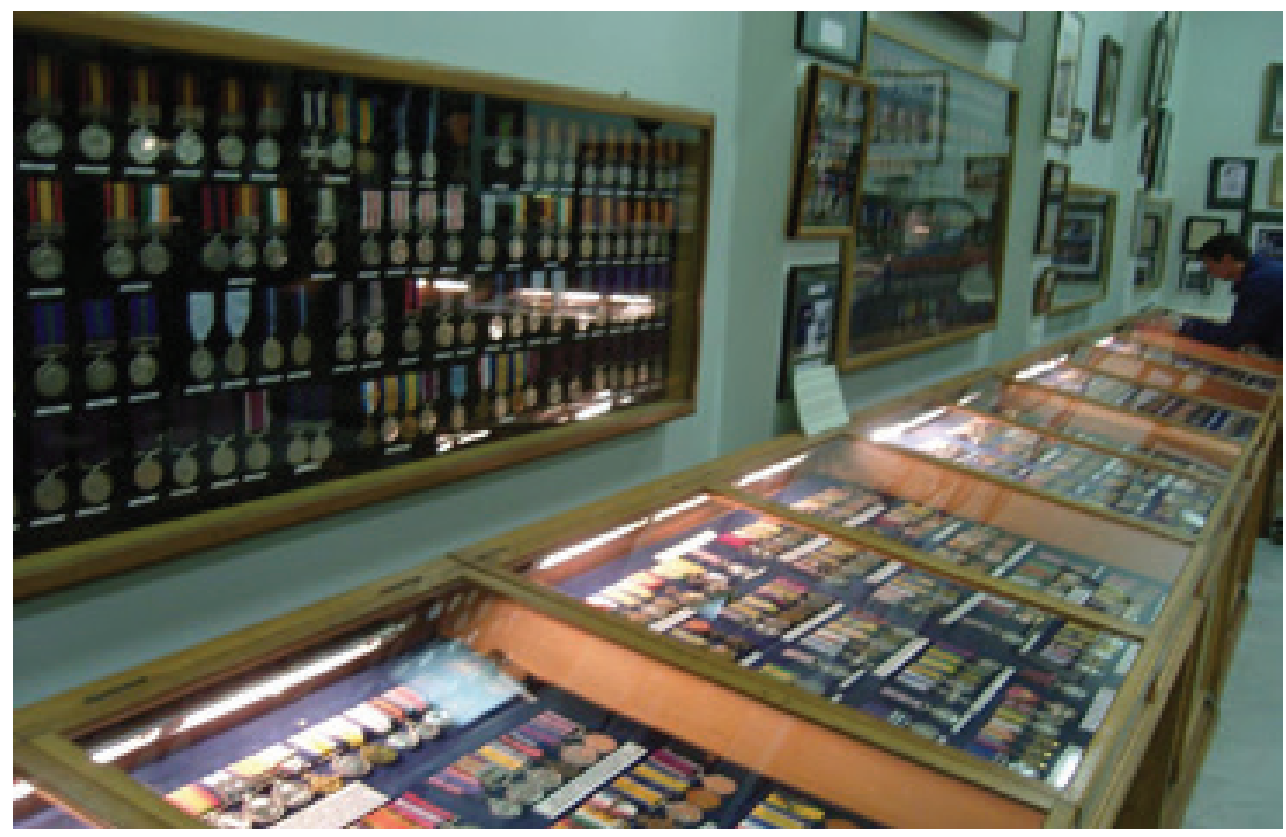

Fig 4. Large amounts of medals in cabinets and frames, courtesy of the Royal Ulster Rifles Museum

Weapons are perhaps the best illustrative example of this approach. One way in which they are 'sanitized' is when they are presented as pieces of technology. Panel text will provide details such as range, calibre and rounds per minute. According to Lubar, by providing these kinds of details, museums are able to absolve themselves of potentially negatively affecting visitors. One feature of the technological approach is to illustrate how this has evolved through time. In this case, weapons are 'abstracted into discreet typological developments' (Jones, 1996), that is, they are arranged chronologically to reflect a gradual improvement in weapon technology. It is interesting that this approach is not a new phenomenon; an early example is that of the Pitt Rivers Museum in the mid-nineteenth century and its arrangements based on the technological progression of weapons (Chapman, 1988).

An example is observable in the Inniskillings Museum, Enniskillen, which has a cabinet containing ten firearms that were used by the British Army, beginning with a matchlock musket and ending with the assault rifle used by today's soldiers.

These objects, like all others, have an original context (Pinney, 2005). Kavanagh (1999) made the point that it is essential to position and understand military objects within their contexts. It has been argued that by presenting weapons as pieces of technology, their original context is made less apparent. In other words, this masks the fact that they were devices used or at least designed to kill people. Raths (2013) described the exhibition of tanks at Germany's Tank Museum, Munster. Large numbers of fully restored tanks were displayed in neat rows without a trace of their former fates in battle. Textual interpretation was offered only in terms of their technical details. Raths argued that this method of display allowed visitors to forget that the tanks were 'built by human beings, were filled with human beings and were used against human beings'. He commented that this 'sterile' method was a way of masking the horrors of war with technical fascination and this made it difficult for visitors to see these objects from other perspectives. 


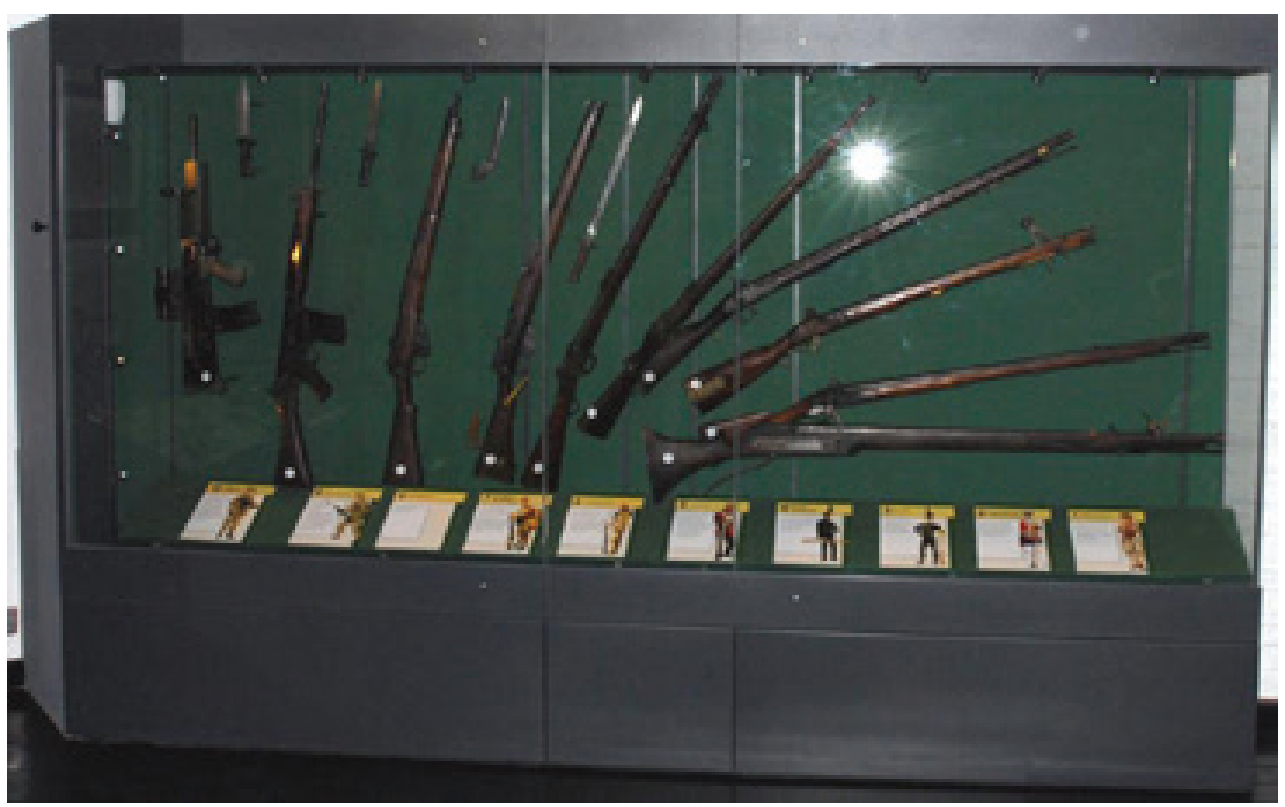

Fig 5. Progression of the technology of rifles, courtesy of the Inniskillings Museum

Raths goes on to argue that efforts to display the tanks differently, to encourage multiple interpretations, is something that the visitors would have to have forced upon them, as many are happy to enjoy the technicality of the object without considering what it did. Winter (2013) also suggested that those who develop fascinations with weapons dislike the display of their violent effects, as this spoils their idealized view of these supposedly thrilling objects.

However, Fitzgerald (1996) asserted that a more critical view of technology should be used in museums. He said that technological exhibits are too celebratory and that some go so far as to resemble propaganda, as the chronological advancement of weapons features an emphasis on improvement and progress. Fitzgerald was also critical of immaculate, overrestored technology, as this further removes the artefact from its original context. Kohn (1995) concluded that the overall effect of presenting weapons as technology is to remove them altogether from moral debate.

Another method of neutralizing weapons, particularly in the case of swords, is to use them as aesthetic objects. An example would be Redkal's exhibition (held at the Museum of Cultural History, Oslo) and subsequent discussion on beautiful weapons (2013). A further example would be the 'Noble art of the sword' exhibition, which featured at the Wallace Collection, London (Lewis, 2012). Here, renaissance swords (which, admittedly, are beautiful objects) were presented as pieces of art or fashion. This way of interpreting weapons is something that Sherman advised against (1995). Baudrillard (2005) also provided a caveat regarding these 'beautiful objects'; he explained that this way of using the objects very much abstracted them from their original functions. However, this raises an interesting question; does this criticism apply to ceremonial weapons, whose intended function is related to display rather than violence?

\section{Violence and 'Realism'}

This third approach to displaying military objects has arguably been a reaction to the approaches discussed above. An early example of this position was the anti-war museum set up by Ernst Friedrich in Berlin, in 1924. His method of displaying brutal images of violence was an intentional divergence from the selective, censored approach of official war museums (Winter, 2013).

Critics of military museums have suggested that military objects should be interpreted with a level of realism. Jones (1996), for example, proposed a more honest appraisal of 
weapons and what their place in war really is. One of the major problems that Bartov outlined was that war museums 'display the tools, not the destruction wreaked by those tools' (Bartov, 1996:155). Jones suggested that a solution to this would be to display artefacts with visible signs of the destruction of war, such as bullet ridden or half-exploded objects. Examples of uniform or armour with ruptures made by weaponry can also be used in this way. However, are these really indicative of what happened to the person who was wearing them? Arguably, they do not go far enough to show the dramatic effect that weaponry can have on the human body, but the display of this through objects can be a difficult task.

A different method would be to use objects such as weapons in combination with other objects or imagery to help the visitor form alternative impressions. Hagemann (2013) discussed how a shell casing was 'recontextualized' when it was arranged with pieces of damaged masonry from the buildings that it hit. Combinations of objects which did not share an original context on the battlefield can be used to provoke thought. A landmine and a prosthetic leg would be an example of such a pairing. Violent objects can also be combined with photographs to achieve a similar effect. An example highlighted by Fitzgerald (1996), was a military transport vehicle at the Museum of Technology and Work, Mannheim. This object was presented as a piece of technological equipment, but next to it was a photograph of the same vehicle containing dead soldiers. This method helps the visitor realize the vehicle's original context and allows for an entirely different set of interpretations.

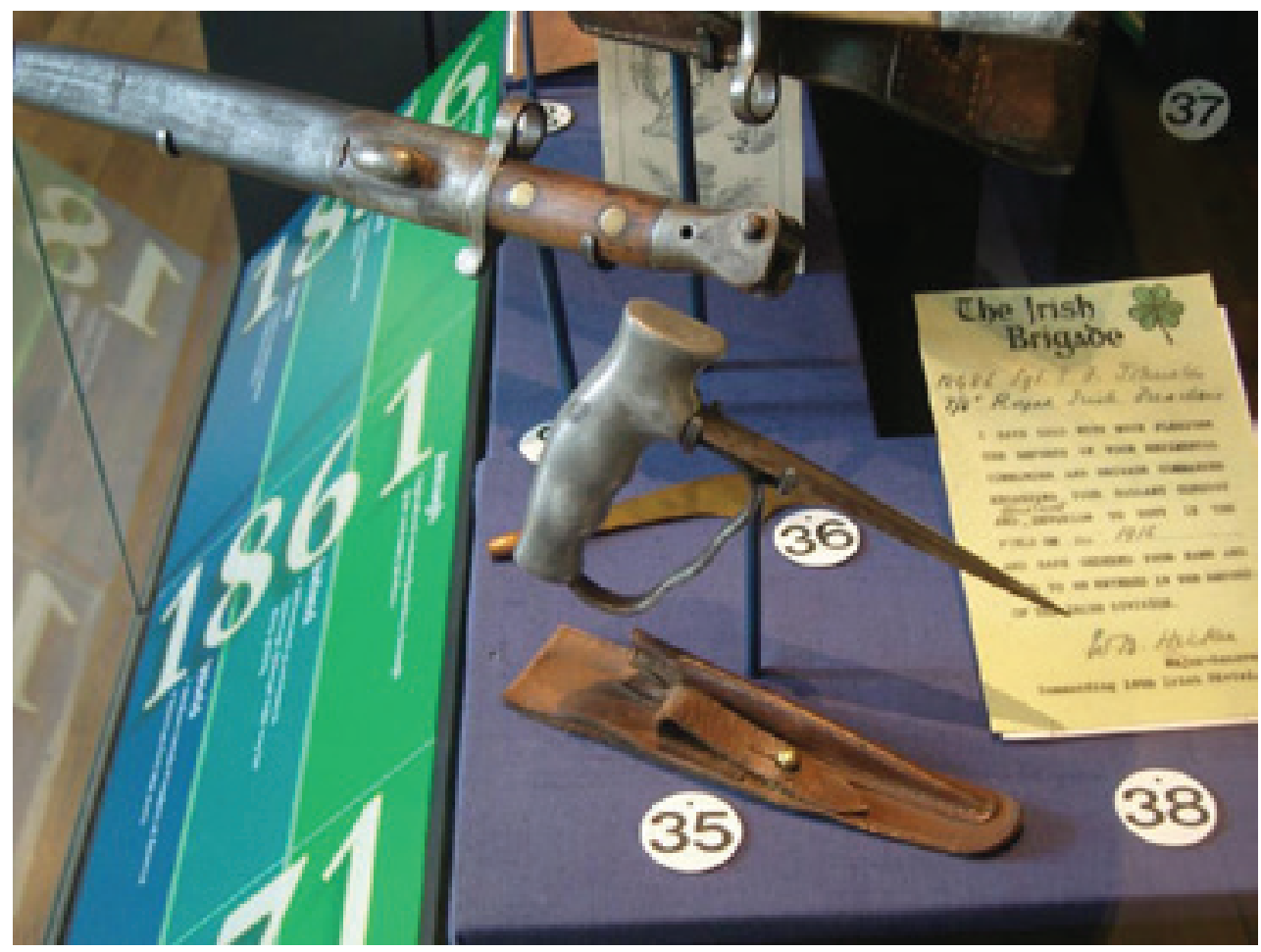

Fig 6 Trench Dagger, courtesy of the Royal Irish Fusiliers Museum

In contrast to the 'beautiful weapons' discussed earlier, it is clear that there are certain weapons that are inalienable from their original functions, as it is clearly visible what their grim purpose was from looking at their shape, physicality or condition. A graphic example is a trench dagger found in the displays at the Royal Irish Fusiliers Museum, Armagh. This device is described as being used on night-time trench raids. The item itself is grotesque, resembling a knuckleduster with a blade protruding out of the 'punching end'. It is also dull and has only been restored minimally. Similar objects can be found in the other museums in the form of dull and worn 
daggers and truncheons with blades attached to them. It is because of the ugliness of the object and its low level of technology, that the visitor can more easily visualize its use. Although these objects could be considered to be upsetting for some visitors, they can provide an important reification of the realities of war.

The impact of weapons can be emphasized more simply, through textual interpretation. An example is an 08/15 Machinegun, used during the First World War, at the Royal Ulster Rifles Museum. The caption that describes this object is actually very realistic and clearly states the significance of the weapon. Instead of putting the object into the context of what harm it can cause an individual, the caption places it in the context of its effect on humankind generally:

The 08/15 [machine gun] was singularly responsible for more casualties on the battlefield than any other weapon, including the atomic bomb. It has truly earned the reputation of the Devil's Paint Brush.

When those curators of the Northern Irish regimental museums were interviewed about the use of weapons in their museums, they voiced differing views regarding how they are interpreted. One believed that 'for most people it's a given as to what weapons were used for'4 and that the sanitized approach was not something they did at the museum. Curator, Amanda Moreno (Northern Ireland Regimental Museums) said virtually the opposite;

You have to have a massive amount of imagination and a fair degree of knowledge of how the weapon actually worked, the size of the bullet and what a bullet actually does to the human body, to see it as something dangerous ${ }^{5}$

Richard Bennett (Inniskillings Museum) was very aware that a technological approach was used at his museum, and explained that they presented,

Weaponry as technology, how it worked, and the evolution of engineering, in an effort not to concentrate too much on the killing aspect of it ${ }^{6}$

A balance has to be addressed when using this approach. Some realism is very useful in displaying the objects of war, but how much is too far? At what point does the overt display of violent objects promote morbid fascination? Raths (2013) discussed how the overt display of violence can actually have a detrimental effect on the learning process if it delivers a shock to the visitor. He advised that visitors should be offered the chance to look at violent imagery to see the effects of war, but only if they make a conscious decision to do so.

\section{Visitor Research}

Efforts were made to explore how the display of weapons in a 'sanitized' manner can affect visitor interpretations. The previously mentioned rifle case at the Inniskillings Museum was used as a means of assessing visitors' interpretations. Participants' word associations were requested in order to gain a view of how they had interpreted these objects. They were asked directly after viewing a particular object or set of objects to provide of the first word that they could think of (relating to what they had viewed). Research was carried out by the author. Sixty visitors were selected on an opportunistic basis. If we are to use the critiques concerning abstraction of function and context, then one would predict that fewer people would provide word associations which reflected the violent side of weapons. The word association results for the rifles are presented in figures 7 and 8 . The words have been analysed in terms of semantics, with similar meanings grouped together. The word cloud provides a quick visual interpretation of the results which are also displayed in full in the accompanying table.

Of the respondents, seven associated the rifles with 'war'; this was the most frequently mentioned single word. This is perhaps indicative of the capability of a rifle in symbolising war itself. There were 24 participants who responded with a negative word (war is included in this) and these are shown in red. There were also eight associations which reflected that the respondent had viewed the weapon in terms of technology or development (shown in dark brown). The words in blue reflect responses related to the rifle as a functional object without any signification. The number and variety of different words is noticeable in this word cloud. This perhaps reflects the notion that (as a focus group later proposed) weapons can be objects 
with many possible interpretations. What we can conclude from this is that different people will generate entirely different interpretations of weapons. It was interesting that some participants immediately saw the more violent nature of the rifles and others were perhaps more interested by the display of the rifles as examples of technology.

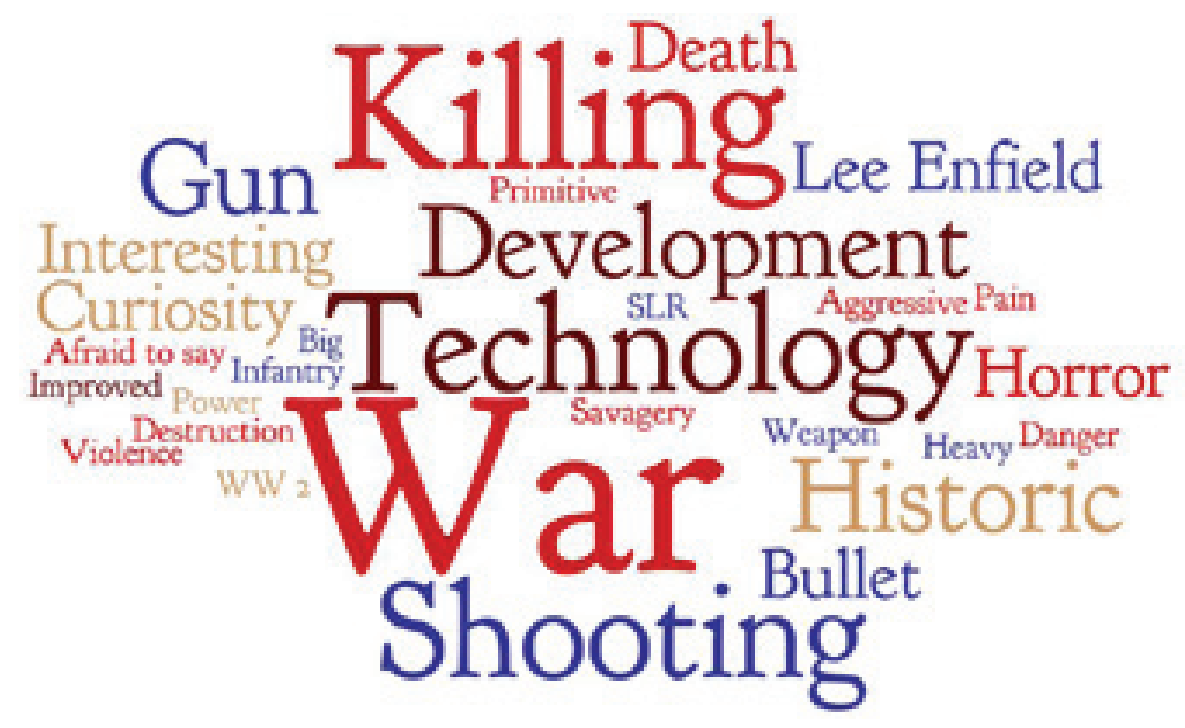

Fig 7. Word cloud depicting word associations

A focus group was carried out at the Inniskillings Museum to attempt to explain some of these results. Ten participants were recruited by the author on a partly opportunistic basis, some of whom were involved in local history groups and others who were friends and family of museum staff. A range of ages and an equal ratio of genders were selected. Participants explained that viewing a weapon in terms of technology was fascinating and that usually they would not have been interested in such objects. They were also adamant that although they could view the object in this way, it did not prevent them from realizing that it had previously been used to kill people. The group were able to explain some of the reasons behind the popularity of the technological approach. One participant commented that 'I'm not interested in guns, but if it was part of an evolution of items it would interest me'. Another explained that 'well you always like to put things into context; it's nice to see progression and innovation'. A further response was that 'You can admire the engineering'. One of the group suggested that more attention should be given to the previous owner of the gun; this is what Gordon (1993) referred to as the 'forward-linkage' component of the object's context, or who the object was used by. This is something that is rarely done with guns, compared to other weapons such as swords, most likely due to the fact that most modern types of firearm were mass produced.

A conclusion that can be drawn from this is that the sanitized approach can be useful in a museum setting. People who have no interest in weapons can nevertheless engage with the objects if they are presented as pieces of art or technology. Regardless of this, is it still ambiguous and misleading to display weapons in this fashion?

\section{Conclusion and Recommendations}

Let us also return to some of the factors that influence how an object contributes to the creation of representations of war. One thing that was highlighted was the way that these objects are connected with people. If museums want to influence a visitor's outlook on conflict by displaying material culture, then surely they should respect those people linked to the objects who actually experienced it. When displaying military objects it is very useful to consider who made it, who 
used it, who it was used upon or who it was taken from. Efforts should be made not only to insert a human presence into objects relating to our military heritage, but also to humanise the enemies that fought against our soldiers. Objects found in the Royal Irish Fusiliers Museum show this in action. The description of the Korean soldier's jacket tells us that it was heavily padded to allow the wearer to endure the freezing temperatures which afflicted 'enemy' and ally alike. Yet it could be said that the adoption of certain approaches to displaying military objects means that the personal element of the objects are lost or become less apparent. Wood (1987:65) made the important point that

Military history is about people... However sophisticated the weapon systems become, the service man and woman will always be there and it is their presence, their story that lies at the root of military history.

Physical condition is something which affects an object's ability to be a display item in all types of museum. It is often the case that objects in regimental museums are in impeccable condition, cleaned and restored to provide a vibrant and colourful display, presenting in turn an exciting, alluring vision of war. Conversely, the use of damaged objects can be used to reflect the ravages of war, though even here care must be taken when displaying these objects, as It can be the case that damaged objects are used in a triumphalist way. An object at the Royal Irish Fusiliers Museum which arguably falls into this category is a piece of metal salvaged from the wreck of a German aircraft. Is the object there to say 'look what we shot down'? These objects can be used to remind us of the destruction caused by war, but they must be presented in a way which respects the victims of conflict.

\begin{tabular}{|c|c|c|}
\hline War & 7 & \\
\hline Killing & 5 & \\
\hline Herrer & 2 & \\
\hline Death & 2 & \\
\hline Aqpressive & 1 & \\
\hline Sovagery & 1 & \\
\hline Primitive & 1 & \\
\hline Afraid to say & 1 & \\
\hline Vislenct & 1 & \\
\hline Pain & 1 & \\
\hline Destruction & 1 & \\
\hline Danger & 2. & 24 \\
\hline Technolecy & 4 & \\
\hline Development & 3. & \\
\hline Improved & 1 & 8 \\
\hline Shootine & 4 & \\
\hline Gun & 3. & \\
\hline Bullet & 2 & \\
\hline Let Lnfield & 2 & \\
\hline SLR & 1 & \\
\hline B specials & 1 & \\
\hline Weapon & 1 & \\
\hline Heary & 1 & \\
\hline Infantry & 1 & \\
\hline Bir. & 1 & 17 \\
\hline Hintorik & 3 & \\
\hline interesting & 2 & \\
\hline Curiosity & 2 & \\
\hline Power & 1 & \\
\hline$W W_{2}$ & 1 & 9 \\
\hline
\end{tabular}

Contexthas been mentioned many times in this paper and it is important to bear in mind the object's original context - the existence of the object during the period of history that it represents. When objects such as weapons are displayed in traditional ways, the original context can be more or less apparent. By explaining the object within other contexts such as art or technology, different individuals can engage with the object in ways that they previously would not have done. However, by doing this, one can also restrict the number of potential interpretations a visitor can make, and it can be the case that the original context is masked. It can be difficult to explain one object within different contexts when attempting to allow for multiple interpretations, when one considers the

Fig 8. Frequency of word associations provided by survey participants for the rifles 
usually concise nature of object labels. It is perhaps more realistic to say that curators should attempt to balance how they place different objects in different contexts within exhibits.

In this paper, objects have been discussed in their more immediate context, that is, their physical context within a museum. The perception of these objects can be influenced heavily by what surrounds them in displays. An object that has the potential to be perceived in terms of it being a trophy may not be such, until it is placed alongside other similar objects that have also been taken on campaign.

It is clear that each of the approaches to displaying military objects discussed in this paper create very different views of war. The most obvious recommendation that can be made is to prevent one of them from dominating entire museums or even exhibitions. Too much realism can present the visitor with a negative experience, yet a small amount of it can be a useful reminder of the brutal realities of war. A completely sanitized view of war can be very misleading, but it can be employed to view potentially controversial objects in more accessible contexts. An entirely celebratory account of a regiment can create a distorted image of war, yet it often makes for more entertaining and attractive displays and it also fulfils many of the roles of a regimental museum. The key is balancing the different approaches to display the many facets and different sides of war. This will create a more even-handed representation of war that is palatable to both civilian and military audiences alike.

Received 15 April 2014

Finally accepted: 30 June 2015

\section{Notes}

1 Richard Bennett, Inniskillings Museum (Interviewed by James Scott at the Inniskillings Museum, 19/6/2012)

2 Jonathon Maguire, Irish Fusiliers Museum (Interviewed by James Scott at the Irish Fusiliers Museum, 14/6/2012)

3 Interview with Amanda Moreno, Curator of the Northern Irish Regimental Museums (Interviewed by James Scott at Carrickfergus Museum, 12/6/2012)

4 Jonathon Maguire (see above)

5 Amanda Moreno (see above)

$6 \quad$ Richard Bennett (see above)

\section{References}

Bartov, O. (1996), Murder in Our Midst: The Holocaust, Industrial Killing and Representation, Oxford University Press, Oxford.

Baudrillard, J. 2005, The System of Objects, 2nd edn., Verso, London.

Cameron, D., F. (1971), 'The Museum, a Temple or the Forum?', Curator: the Museum Journal, 14, (1) 11-24.

Cornish, P. (2004), 'Sacred relics': Objects in the Imperial War Museum 1917-39' in Saunders, N. J., Matters of Conflict: Material Culture, Memory and the First World War, 35-51, Routledge, Oxford.

Department of Culture and Leisure Northern Ireland, 2011, Museum policy Document.

Dubin, S., C. (1999), Displays of Power: Memory and Amnesia in the American Museum, New York University Press, New York. 
Dudley, S., H. (2010), 'Museum Materialities: Objects, Sense and Feeling' in Dudley, S., (ed), Museum Materialities: Objects, Engagements, Interpretations, 1-19, Routledge, Oxford.

Fitzgerald, L. (1996), 'Hard Mean, Hard Facts and Heavy Metal: Making Histories of Technology' in Kavanagh, G., (ed), Making Histories in Museums, 116-130, Leicester University Press, Leicester.

Gieryn, T., F. (1998), 'Balancing Acts' in Macdonald, S., (ed), The Politics of Display: Museums, Science, Culture, 197-228, Routledge, London.

Gordon, R., B. (1996), 'The Interpretation of Artefacts in the History of Technology' in Kavanagh, G., Making Histories in Museums, 74-93, Leicester University Press, Leicester.

Hagemann, S. (2013), 'The Bomb and the City: Presentations of War in German City Museums' in Muchitsch, W., (ed), Does War Belong in Museums?, 131-145, Transcript Verlang, Bielfield.

Hicks, D. \& Beaudry, M., C. (2010), The Oxford Handbook of Material Culture Studies, Oxford University Press, Oxford.

Jabri, V. (1996), Discourses on Violence: Conflict Analysis Reconsidered, Manchester University Press, Manchester.

Jones, S. (1996), 'Making Histories of Wars' in Kavanagh, G., Making Histories in Museums, 152-163, Leicester University Press, Leicester.

Kavanagh, G. (1999), 'Making Histories, Making Memories' in Kavanagh, G., Making Histories in Museums, 1-15, Leicester University Press, Leicester.

(1994), Museums and the First World War: A Social History, Leicester University Press, Leicester.

Kohn, R. (1995), 'History and the culture wars: The case of the Smithsonian Institution's Enola Gay exhibition', Journal of American History, 82(3), 1036-1063.

Lubar, S. (1997), 'Exhibiting Memories' in Henderson, A., and Kaeppler, A., Exhibiting Dilemmas: Issues of Representation at the Smithsonian, 15-27, Smithsonian Institution Press, Washington, DC.

O'Brien, M.E., (1997), 'Aestheticizing War: Eduard von Borsody's Wunschkonzert', Seminar: A Journal of Germanic Studies, 33(1), 36 - 49.

Pearce, S., M. (1999), On Collecting: An Investigation into Collecting in the European Tradition, Routledge, London.

Pinney, C. (2005), 'Things Happen: Or, From Which Moment Does That Object Come?' in Miller, D., (ed) Materiality, 56-273, Duke University Press, USA.

Raths, R. (2013), 'From Technical Showroom to Full-Fledged Museum: The German Tank Museum Munster' in Muchitsch, W., Does War Belong in Museums?, 83-91, Transcript Verlang, Bielfield.

Redkal, B. (2013), 'About the Beauty of War and the Attractivity of Violence' in Muchitsch, W., Does War Belong in Museums?, 123-131, Transcript Verlang, Bielfield.

Sandell, R., (2003), Museums, Society, Inequality, Routledge, London. 
Saunders, N., J. (2004), Matters of Conflict: Material Culture, Memory and the First World War, Routledge, Oxford.

(2002), 'Memory and Conflict' in Buchli, V., (ed), The Material Culture Reader, 175-181, Berg publishing, Oxford.

Sherman, D., J. (1995), 'Objects of Memory: History and Narrative in French War Museums', French Historical Studies, 19(1), 49-74.

Walker, J. (1997), 'Acquisition, Envy and the Museum Visitor' in Pearce, S. M., (ed) Experiencing Material Culture in the Western World, 255-263, Leicester University Press, Leicester.

Whitmarsh, A. (2001), "We Will Remember Them': Memory and Commemoration in War Museums', Journal of Conservation and Museum Studies, 7, 11-15.

Winter, J. (2013), 'Museums and the Representation of War' in Muchitsch, W., (ed), Does War Belong in Museums?, 21-41, Transcript Verlang, Bielfield.

Wood, S. (1987), 'New Directions in Military Museums', Museums Journal, 87(2), 65-75.

*James Scott works at the Royal Engineers Museum, Gillingham, as Deputy Curator. His major responsibilities involve managing the exhibitions program and also developing the Museum's permanent displays. Before that he worked in a small local history museum in Bangor, Northern Ireland. Whilst there, he also studied his Masters in Cultural Heritage and Museum Studies at the University of Ulster. Here, his research was focused on the military museums of Northern Ireland. Before this, he studied History at Newcastle University. Prior to this he was educated and grew up near Chester, Cheshire.

\section{James Scott}

Deputy Curator (Exhibitions and Galleries)

Royal Engineers Museum, Library \& Archive

Prince Arthur Road,

Gillingham,

Kent ME4 4UG

Tel: 01634822221

deputy-curator@rhqre.co.uk 